\title{
CHANGES IN ACADEMIC RESEARCH PERFORMANCE OVER TIME: A Study of Institutional Accumulative Advantage
}

\author{
Richard Bentley and Robert Blackburn
}

This study examines changes in institutional research performance over time by analyzing data from four national surveys of the American professoriate conducted between 1969 and 1988. To assess whether groups of institutions may be accumulating advantage relative to others, research activities are compared across five Carnegie institution types. Weights are created to adjust for sampling differences and research output measures are standardized to adjust for variation by discipline. Findings show an overall strengthening of research emphasis reflected by a stronger orientation toward research (more faculty holding Ph.D.'s and having a primary interest in research) and higher research output (grant and publication performance). While Research-1 universities have retained their initial (1969) advantage, they have not accumulated more. Meanwhile, Doctoral-Granting-I universities have gained strength relative to Research-il institutions. Research at Comprehensive-I was also up, but at a slower rate than the other Carnegie groups.

As research expenditures have risen, some observers of the higher education enterprise worry about a growing stratification in academic science such that only a few elite institutions are capable of conducting high-quality research. Smith and Karlesky (1977) found that less eminent research institutions are more susceptible to declines in external funding sources, reductions in research opportunities for younger scientists, and deterioration of instrumentation. A general decline in faculty working conditions, such as inadequate supplies and insufficient clerical help (Bowen and Schuster, 1986, p. 156), may be especially burdensome at comprehensive colleges and universities where faculty balance research interests with higher teaching loads.

Another example of strained competition between the so-called "have" and the "have not" institutions is evidenced by the growing dissatisfaction with

Richard Bentley and Robert Blackburn, University of Michigan, 2117 School of Education Bldg., Ann Arbor, MI 48109. 
federal peer review. A number of universities have circumvented competitive scientific review by hiring outside lobbyists and seeking direct legislative sponsorship (Graves, 1986; McCarthy, 1986). Some groups (e.g., the Association of American Universities that represents the largest research universities) criticize this approach as "pork barrel" and warn that it could harm the peer review process, the hallmark of the scientific community (Graves, 1986). However, others counter saying that peer review unfairly favors a select group of eminent research institutions (Rose, 1986).

Despite concerns about growing stratification, longitudinal studies documenting changes in academic research performance by institutional type are rare. For example, science trend data collected by the National Science Foundation (1987) and the National Research Council (1987) do not differentiate by college type. While a number of national faculty surveys provide comprehensive data on higher education (e.g., see literature reviewed by Blackburn, Lawrence, Ross, Okoloko, Bieber, Meiland, and Street, 1986), attempts to combine these data for longitudinal analysis have been hampered by variations in sampling framework and survey question design (see Drew and Tronvig, 1988).

The purpose of this study is to examine changes in institutional research performance over time by analyzing data from four national surveys of the American professoriate conducted between 1969 and 1988. To assess whether groups of institutions may be accumulating advantage relative to others, research output is compared across five Carnegie (1973, 1976, and 1987) institution types: Research-I (Res-I), Research-II (Res-II), Doctoral-granting-I (Doc-I), Doctoral-granting-II (Doc-II), and Comprehensive-I (Comp-I) institutions. Weights are created to adjust for sampling differences and research output measures are standardized to adjust for variation by discipline. ${ }^{1}$

\section{THEORETICAL FRAMEWORK}

Stratification emerges as a central theme in studies on academic research performance (Cole and Cole, 1973; Merton, 1968; Zuckerman, 1977). However most of this research focuses on the hierarchy of individuals rather than institutions (Cole and Cole, 1973; Lazarsfeld and Thielens, 1958; Lotka, 1926; Price, 1963). For example, in 1926 Lotka posited his "inverse square law of scientific productivity" explaining why a few scientists account for most publication productivity.

Accumulative advantage is frequently cited as one reason why some individual researchers achieve eminence over others (Allison and Stewart, 1974; Cole and Cole, 1973; Merton, 1968; Zuckerman, 1977). Put simply, this theory suggests that the rich get richer as they accumulate advantage in terms of resources and recognition. As such, resources and recognition act as feedback 
loops that contribute to subsequent research support and productivity. A good example of accumulative advantage is Zuckerman's (1977) profile of Nobel laureates who are more likely to attend elite universities, study with prestigious mentors, graduate earlier, and be hired by elite institutions. Accumulative advantage is seen as an important factor in explaining why faculty publication and output varies so markedly (Allison and Stewart, 1974; Cole and Cole, 1973).

However, advantage can accrue to institutions as well as individuals. This situation is illustrated by the lion's share of federal support and super-star researchers (e.g., Nobel laureates) concentrated at top research universities. Institutional prestige can act as a "halo effect," thereby providing an additional edge in the grant and publication peer review process (Cole, Rubin, and Cole, 1978; Rose, 1986). The strong predictive power of institutional type and prestige on publication output indicates the important relationship of institutional affiliation. (See the literature reviews by Finkelstein, 1984 and Creswell, 1985.) For instance, a longitudinal study by Long (1978) found that publication patterns changed when natural scientists moved to new institutions, and they reflected the publication norms of the new institution. That is, if they moved to a university of highly productive faculty, they increased their output.

\section{METHODOLOGY}

The study explores two aspects of institutional academic research: (1) general research orientation or potential and (2) overall research output. Changes in research orientation or potential are based on (1) the percent of faculty holding $\mathrm{Ph} . \mathrm{D}$.'s and (2) the percent of faculty with a primary interest in research (over teaching). Changes in research output include (1) the proportion of faculty receiving sponsored research support (from government, industry, and foundations), (2) the level of faculty publication productivity (two-year publications and total books published), and (3) an aggregate measure of research output combining grants, two-year publications, and books.

Data are drawn from four national surveys of the American professoriate. The first two were sponsored by the Carnegie Commission on Higher Education in 1969 (Bayer, 1970; Trow, 1975) and 1975 (Roizen, Fulton, and Trow, 1978). The 1980 survey was conducted by the University of California at Los Angeles' Higher Education Research Institute (1983). The 1988 survey was conducted by the University of Michigan National Center for Research to Improve Postsecondary Teaching and Learning (Blackburn and Lawrence, 1989). 


\section{THE POPULATION}

Table 1 presents the distributions of institution and faculty subsamples by Carnegie type. The subsamples include all assistant, associate, and full professors with principal teaching appointments in eight departments (biology, chemistry, English, history, psychology, sociology, political science, and mathematics/statistics). These departments represent the humanities, natural sciences, and social sciences.

Despite two revisions of the Carnegie classification since 1973 (in 1976 and 1986), considerable institutional stability was found within Carnegie type across survey years. The most significant fluctuation occurred with the redefinition of Res-I universities in 1987. However, all seven Res-I universities in the 1988 sample were also Res-I universities in 1976.

Much of the variation in institution and faculty sample sizes reflects differences in sampling design. For example, the large percentage of Res-I faculty in 1969 reflects the overrepresentation of high-rated universities in 1969 (Roizen, Fulton, and Trow, 1978, pp. 320-323). Of greatest concern is the potential response bias with the 1980 data that has a relatively low response rate $(34 \%){ }^{2}$ The concern is illustrated by the differences in faculty distribution between the 1969 and 1980 subsamples (see Table 1). These two distributions should be similar because the 1980 survey replicated the 1969 sampling framework and drew a representative one-third subset of the same institutions that participated in 1969 (HERI, 1983). However, the 1980 distribution suggests a lower response rate for Res-I faculty. (There is evidence that the HERI subsample was not random.)

\section{WEIGHTING}

Weights were created to adjust for sampling differences across the four survey subsamples. Table 2 presents both the weighted and unweighted sample $N$ 's by Carnegie type, control, and department. The weights are designed to estimate the true distribution of faculty and are based on faculty data reported in the American Universities and Colleges directories (1968, 1983, and 1987). ${ }^{3}$ Random samples by Carnegie type and control were drawn from three directories that corresponded closest to the 1969,1980 , and 1988 survey years. The 1975 weights were interpolated because the directory had ceased publication between 1972 and 1983.

\section{VARIABLE DEFINITIONS AND PROCEDURES}

Measures of research potential and output are based on six survey questions 


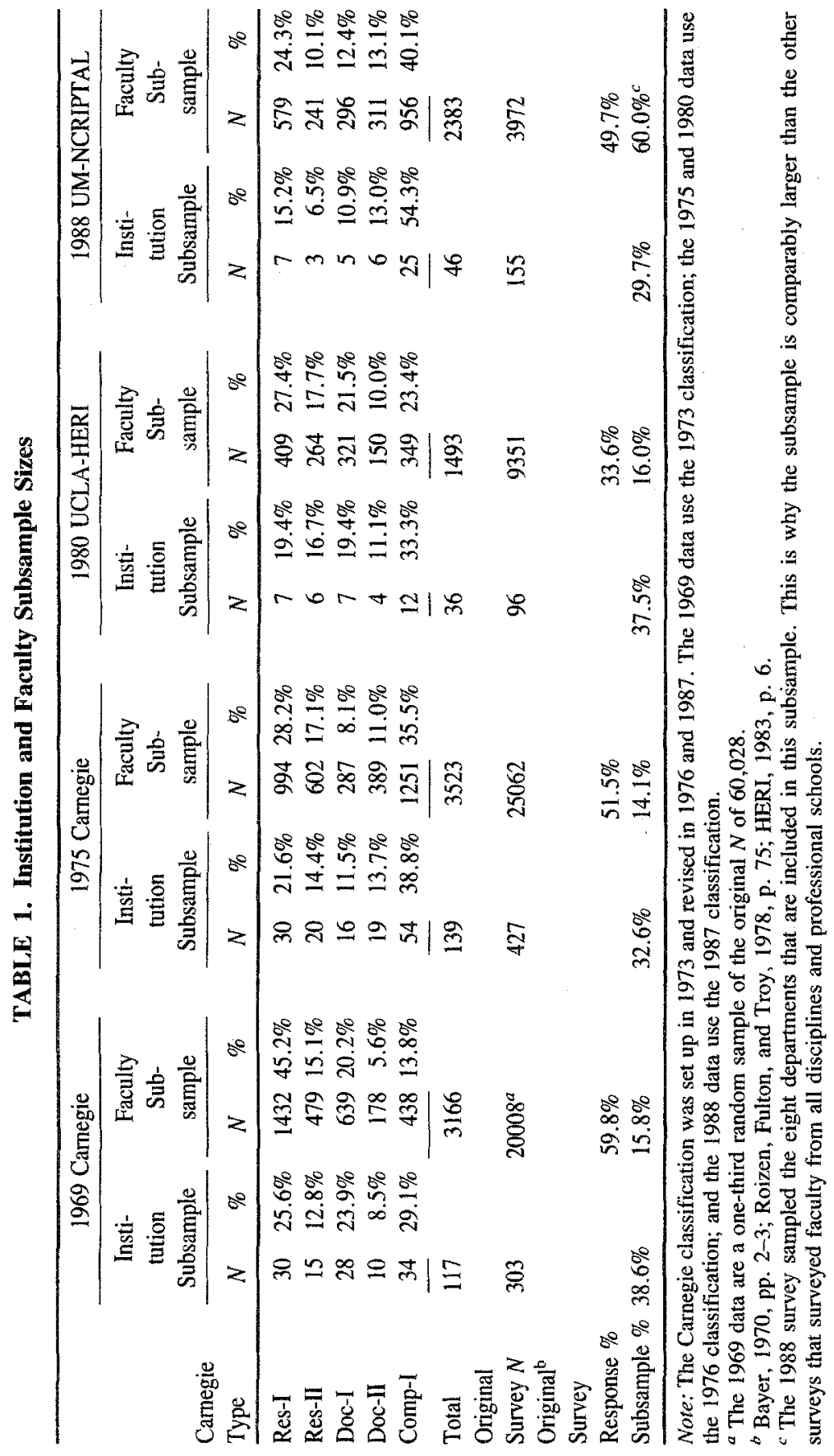




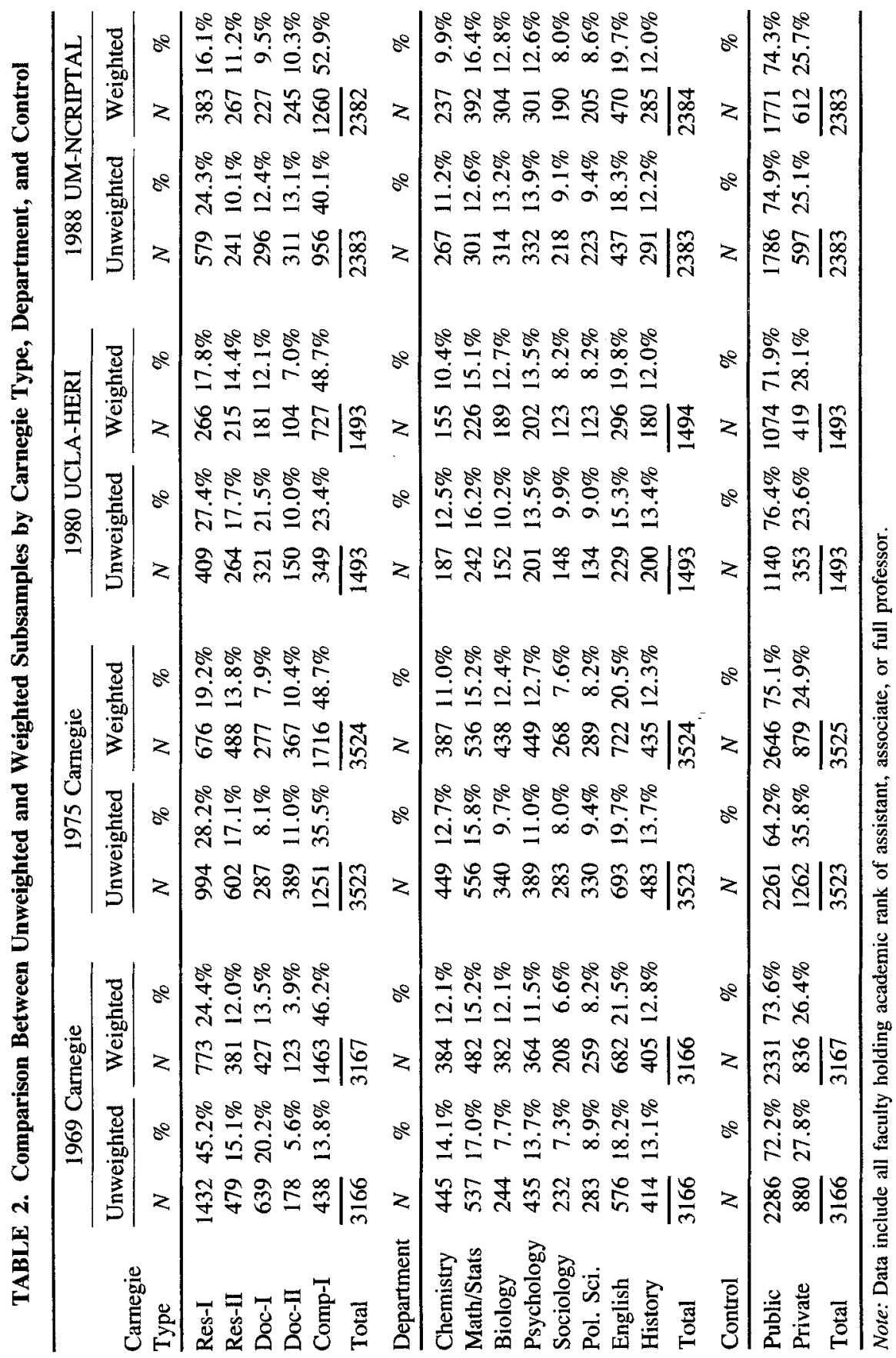


repeated across survey years (only one variable, faculty preference for research, is missing in 1980). Specific variable definitions include the following:

1. PHD-Percent of faculty holding a Ph.D.

2. RESPREF-Percent of faculty primarily interested in research. Of four possible categorical responses, this variable combines faculty reporting interests either (1) leaning very heavily toward research or (2) both in teaching and research but leaning more toward research.

3. PUB2YR-Number of self-reported professional writings published or accepted for publication in the last two years. This variable was recoded into mean categorical values to estimate the actual number of publications (i.e., a category indicating a range of 5 to 10 publications was recoded 7.5). ${ }^{4}$

4. BKSALL-Number of books and monographs published over a faculty member's career. Like PUB2YR, this variable was recoded into mean categorical values (i.e., a category indicating a range of 3 to 4 publications was recoded 3.5). Lifetime books are included, in addition to two-year publications, because the disciplinary norms in some fields (e.g., political science) place more emphasis on books than articles (Biglan, 1973). At the same time, inclusion of BKSALL will be influenced by the aging of the faculty work force, which has increased since 1969, since lifetime publications are correlated positively with career experience (Bayer and Dutton, 1977).

5. ALLGRT-Percent of faculty receiving any externally sponsored grant support within in the past year. This dichotomous variable (yes or no) was created by computing a new variable that summed five possible sources of support: federal, state and local government, industry, foundation, and other sources. 5

6. TOTPROD-Aggregate grant and publication output was developed by combining standardized scores from three variables: two-year publications (PUB2YR), total books (BKSALL), and sponsored research support within the past year (ALLGRT). ${ }^{6}$

In addition to presenting mean and percent figures, publication and grant output variables are converted into standardized $z$-scores. Standardized scores avoid potentially overstating performance for those institutions where a disproportionate share of faculty may have been in departments with higher than average publication rates and sponsored research. Standardization also adjusts for publication norms that often vary by discipline (Blackburn, Behymer, and Hall, 1978; Wanner, Lewis, and Gregorio, 1981).

To standardize publications and grants, $z$-scores were created separately for each of the eight disciplines and then summed across disciplines. A new $z$-score is then created from the sum of scores across disciplines. Standardized scores 
for total productivity (TOTPROD) were created by summing the three standardized scores for two-year publications (PUB2YR), lifetime books published (BKSALL), and total grants received within the past year (ALLGRT) and creating a new $z$-score from the aggregate measure.

Findings are presented both in raw data form and as standardized $z$-scores in order to provide a more solid context to assess changes over time. ANOVAs were run across Carnegie types and include Scheffe post hoc multiple-range tests to compare differences between groups.

\section{CAUTIONS AFFECTING INTERPRETATION}

In conducting these analyses several assumptions have been made that could potentially affect the measures that have been used. The principle ones are pointed out and their likely consequences are indicated.

1. Summing individual departmental faculty productivity and taking that average as the measure of department faculty output clearly is a change in the level of analysis, from the individual to the organizational. Summing departments across institutions to calculate a productivity measure for an institution type raises the level of analysis one level higher and encompasses the same potential pitfalls. Both of these procedures were used here even though the complications are known (see Young, Blackburn, Conrad, and Cameron, 1989).

Two scenarios illustrate the possible distortions in the construct. Suppose eight faculty in a department have produced 40 articles in the past two years. If all eight published 5 articles (or even 4 or 6 ) the construct of department productivity as the sum of the individuals seem appropriate. However, if the 40 articles were produced by two faculty and six did nothing (or some similar distribution with a high skewness and standard deviation), one now has a couple of highly productive individuals but not really a productive department. A similar example could be constructed by summing institutions within a type to compare with another type. Whether it makes conceptual sense to add and average institutional productivity units, irrespective of the arithmetic ease of the process, depends on the variance of the sample being summed.

A problem with relying on Carnegie type as the unit of analysis is that research performance can differ significantly across institutions within the same classification type. ANOVAs run on 1988 two-year publications by institution yielded significant differences $(p<.05)$ for four of the five Carnegie groups included in the study. Only Doc-I institutions $(p<.05)$ did not vary across institutions $(p=.17)$. This suggests some caution in assuming similarity in research performance within Carnegie classifications.

On the other hand, research performance levels when compared within departments appear to be more similar. ANOVAs run on 1988 two-year 
publications by department (for Res-I only) showed no significance at six out of eight departments (e.g., ranging from $p=.36$ for sociology to .70 for political science). However, 1988 mathematics $(p<.05)$ and biology $(p<.01)$ departments showed significant difference across institutions.

2. The dollar values of the grants that faculty have received are not known, only the number of grants (as self-reported). ${ }^{7}$ The dollar amount is no doubt higher in later years, except in 1975, where the National Science Foundation (1981, p. 76) clearly shows a decrease in most funding sources, especially at the federal level, which is the highest contributor. However, the value of succeeding dollars from a 1969 standard is clearly less. Also the real costs of conducting research may be higher today. In short, the quantitative consequences of an increased number of grants (i.e., research support) are most likely overestimated by the data.

3. A subtle but not unimportant consideration is the possible changing value of an article at different points in time. Both the amount of journal space available to publish in and the number of faculty seeking to publish in that space differ at each point in time. That is, article values can change. Bieber and Blackburn (1989) have found that when the ratio of space to potential contributors is determined for 1972 (the base year they used) each article must be deflated by about one-half. Said another way, our reported increased productivity is misleading, at least in this respect. ${ }^{8}$

Despite these limitations to this inquiry, one can still retain a high degree of confidence in the results that indicate different growth rates across institutional types, that is, accumulative advantage, since the potential distorting causes for the most part should be nearly random throughout all institutional types.

\section{RESULTS}

Findings are reported in four parts. First, changes in research orientation and potential of campuses to accumulate research advantage are shown (Figures 1 and 2, with Tables A1 and A2). Second, indices of research publication output, including two-year publications and lifetime books published, are presented (Figures 3-6 with Tables A3-A6). Third, grant acquisition is displayed (Figures 7 and 8, with Tables $A 7$ and A8). Fourth, an aggregate measure of research output that combines grants and publications is shown (Figure 9, with Table A9). Last, a summary of Scheffe tests findings on the grant publication variables is presented in Table 3 .

\section{Research Orientation}

In general, the data suggest a growing emphasis on research orientation and 
potential. This observation is supported by the growing number of faculty holding Ph.D.'s as well as the increasing percentage of faculty whose interest in research is greater than in teaching ${ }^{9}$ (see Figures 1 and 2). A growth in Ph.D. faculty was most marked at Comp-I institutions between 1969 and 1975 (up from $72.9 \%$ to $84.5 \%$ ), although this rate of growth has since tapered. Doc-II institutions also increased (from $82.9 \%$ to $92.9 \%$ between 1969 and 1980). This larger growth rate, of course, was made possible because of their lower initial percentage.

Of all five Carnegie groups, Doc-I and Doc-II showed the greatest increase between 1969 and 1975 of the proportion of faculty with primary interest in research. Doc-I's rose from $43.7 \%$ to $55.1 \%$ during this time, while Doc-II's rose from 23.1 to $41.9 \%$. Comp-I's show little change in research interests despite their growth in percentage of faculty with $\mathrm{Ph} . \mathrm{D}$.'s

\section{Publication Performance}

Faculty publishing rates have risen at all types of institutions since 1969 (see Figure 3). For example, the mean number of two-year publications at Res-I universities rose from 3.7 to 5.2 between 1969 and 1988 (see Table A3). Doc-I's have expanded two-year publication output considerably, especially between 1969 and 1980 (rising from an average of 2.9 to 3.8 articles), and surpassed Res-II universities for that moment in time.

A similar picture emerges after two-year publication figures are standardized by discipline before summing (see Figure 4). Standardized two-year publication

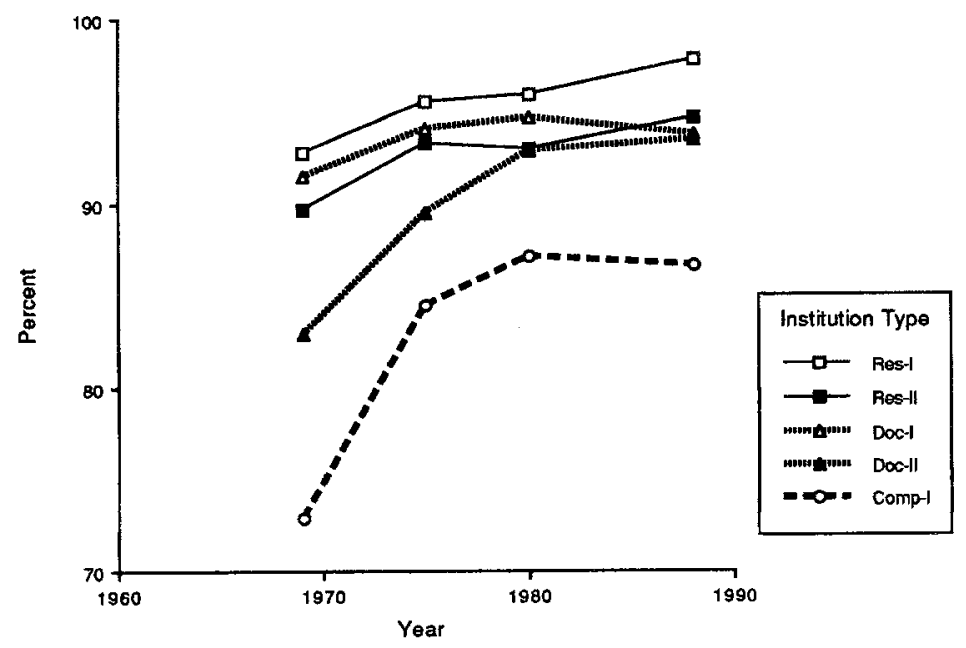

FIG. 1. Percent of faculty with Ph.D.'s. 


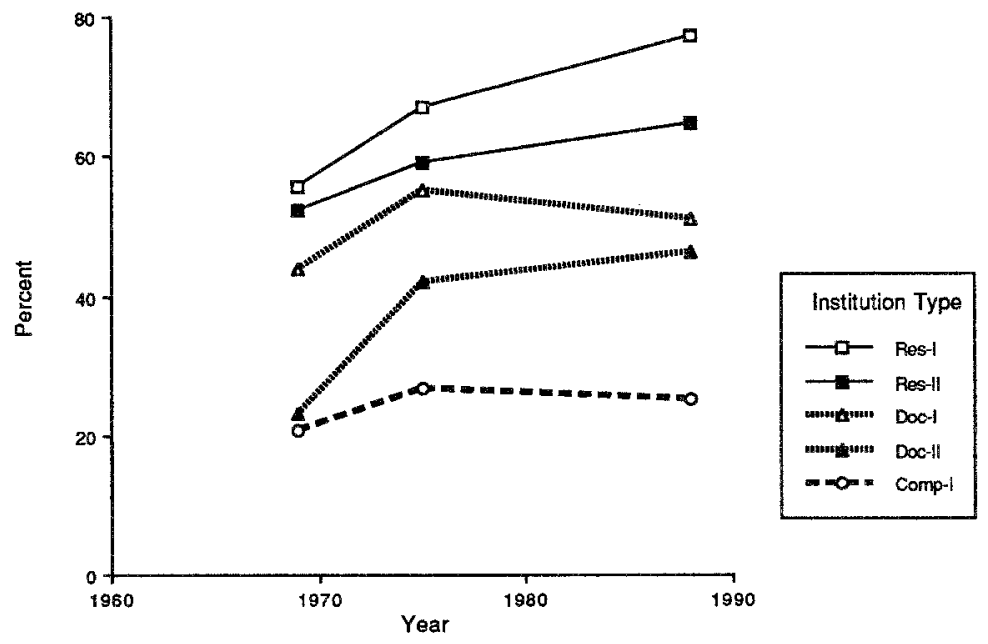

FIG. 2. Percent of faculty primarily interested in research.

data suggest even a more pronounced gap between Comp-I and other institutions. A Scheffe post hoc test shows a significant difference between Comp-I and Doc-II's $(p<.05$ ) beginning in 1975 (see Table 3).

Lifetime book publication totals also have risen since 1969. For example, the mean number of books published at Res-I's rose from 1.4 to 2.0 (see Table A5). As with two-year publications, there appears to be a strong parallel in book

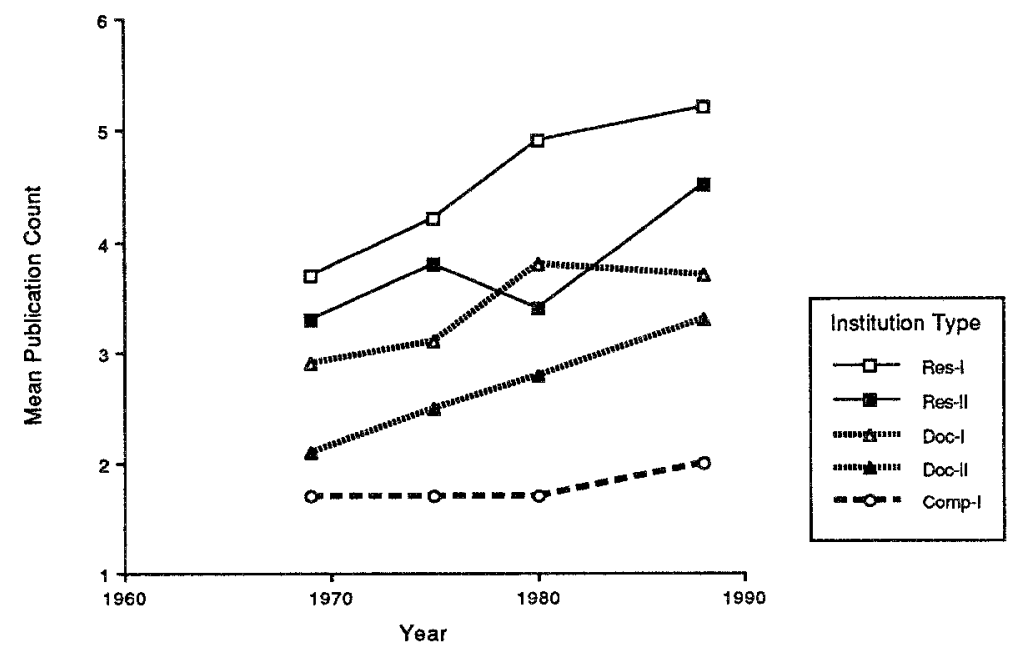

FIG. 3. Mean two-year professional publication rate. 


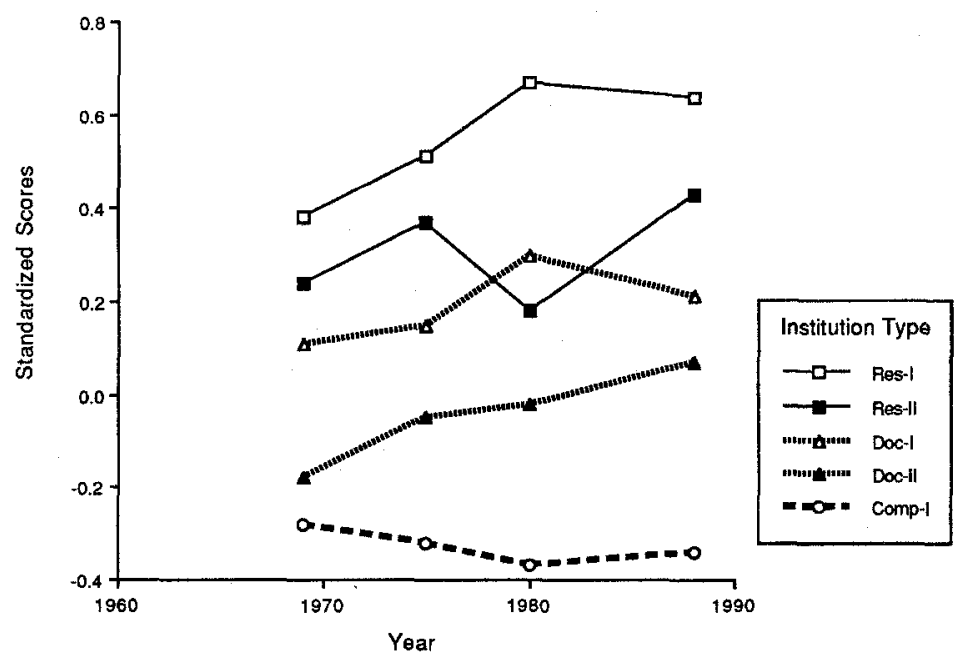

FIG. 4. Standardized two-year professional publication rate (adjusted for differences by discipline).

publication rates between Res-II and Doc-I institutions. Figure 5 shows how both institution types rose between 1975 and 1980 (from 1.3 to 2.1 and from 1.2 to 1.8 , respectively) and dropped in 1988 (both to 1.5 ).

The same trend between Res-II and Doc-I institutions emerges when mean book publication rates are converted into standardized scores to adjust for differences by discipline (see Figure 6 and Table A6). Again a parallel movement is evident. Meanwhile, standardized mean book publications show a steady increase in Doc-II's between 1969 and 1988 compared to the decline at Res-II's and Doc-I's after 1980.

\section{Grant Support}

The percent of faculty receiving federal support is slightly higher in 1988 than in 1969 . In 1988 , for example, $56.3 \%$ of the Res-I faculty sampled reported receiving federal support compared to $47.2 \%$ in 1969 . Similarly, slight increases were reported by faculty in the other institutional groupings. (See Figure 7 and Table A7.) The federal curtailment of the 1970s is shown for all but the Res-II universities.

Once again Doc-I's appear to be an increasingly strong contender with Res-II in the ability of their faculty to compete for grants from government, industry, and foundations. This same trend is not diminished when the grant data are standardized. (Compare Figures 7 and 8 and Tables A7 and A8).

Comparing standardized grant support by Carnegie-type shows that Res-I universities have declined steadily since 1975 while Res-II and Doc-I 
TABLE 3. Scheffe Post Hoc Tests Significant at .05 Comparing Differences by Carnegie Institution Type

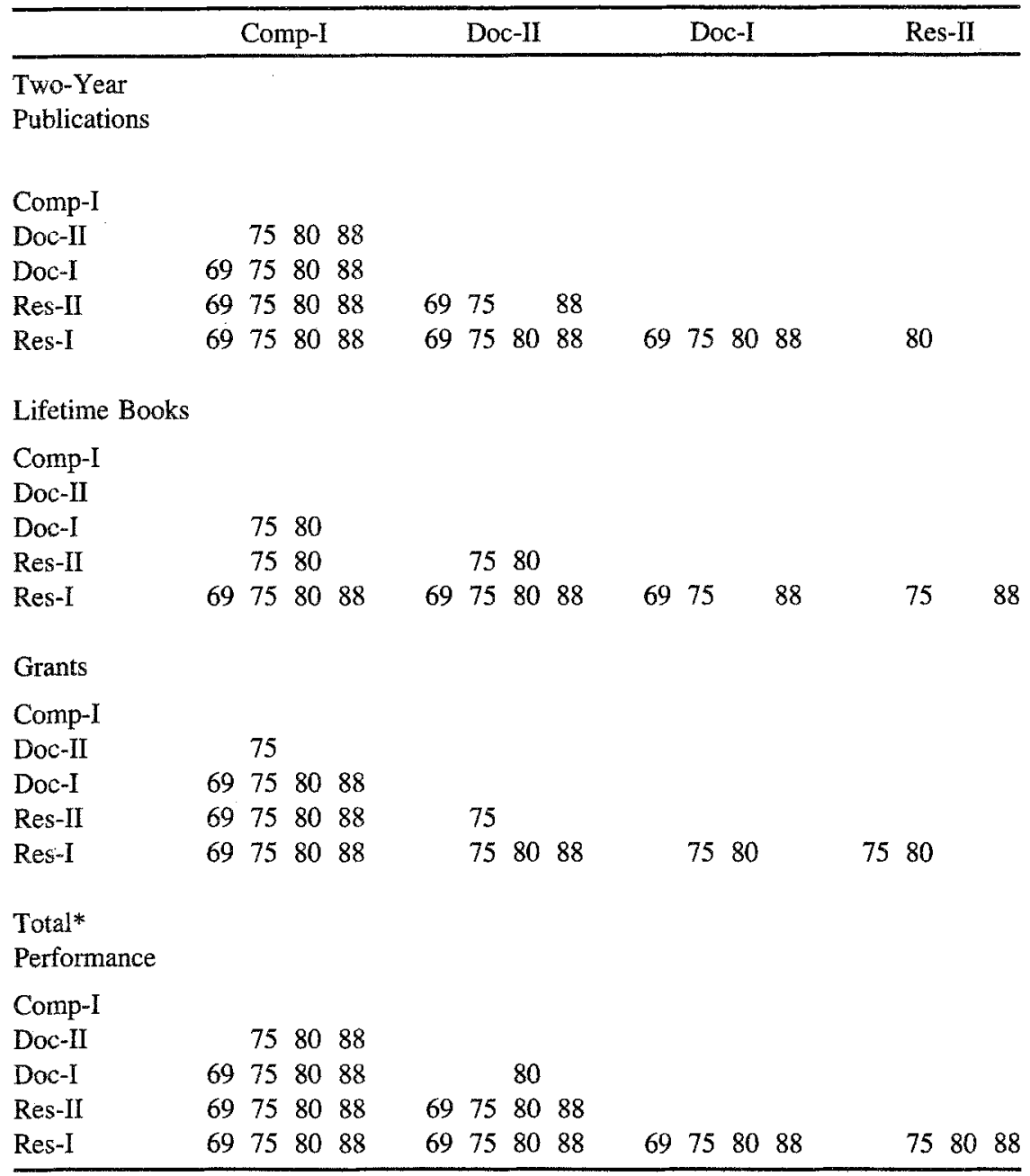

* Combines grants, two-year publications, and lifetime books.

Note: All ANOVA $F$-scores significant $(p<.001)$. Scheffe test pairs of Carnegie groups different at the .05 level. Significant differences are identified by survey year (e.g., $75=1975$ survey data).

institutions have remained steady. Scheffe tests showed significant differences $(p<.05)$ between Res-I and all other Carnegie groups in 1975 and 1980, and in 1988 Scheffe tests showed no significance among Res-I, Res-II, and Doc-I institutions (see Table 3). This erosion of Res-I grants supports the argument that "pork barreling" may be taking grants that used to go to Res-I's in a peer 


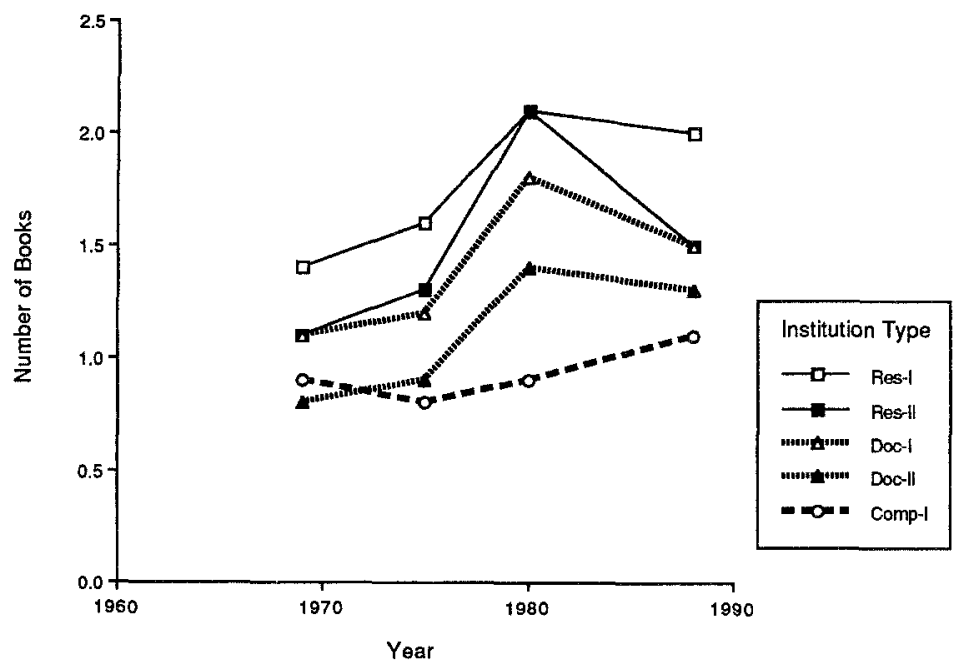

FIG. 5. Lifetime books published.

review process and may be giving them to institutions that received less in the past. (As noted before, we do not have dollar amounts and Res-I's may even be gaining in total funding even if number of grants has declined. They can be the recipients of the larger dollar awards.)

\section{Total Publication and Grant Output}

As with changes in publications and sponsored grants, Doc-I institutions

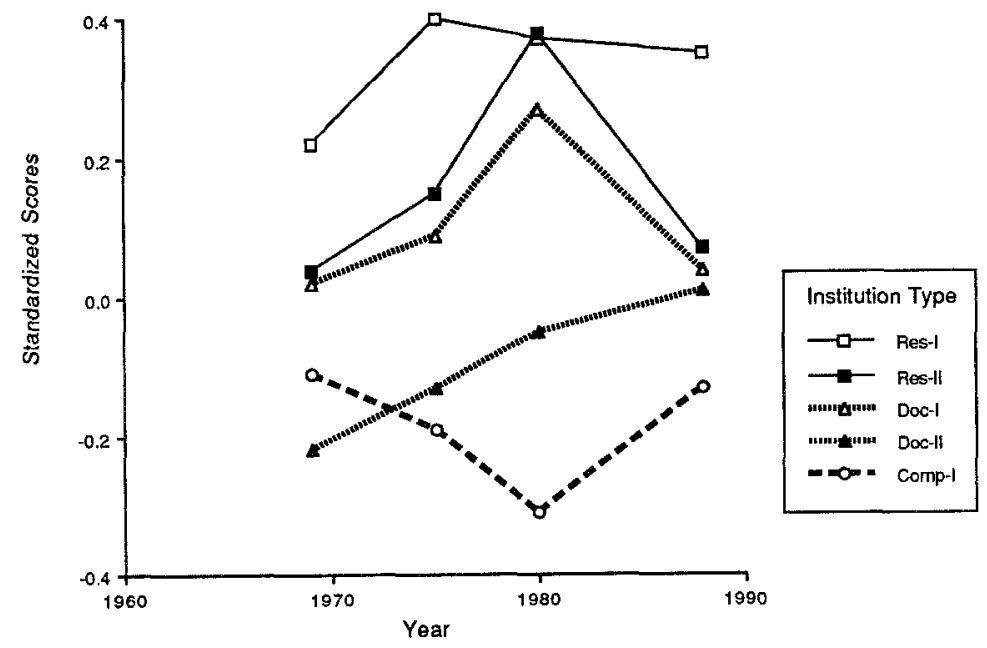

FIG. 6. Standardized books published (adjusted for differences by discipline). 


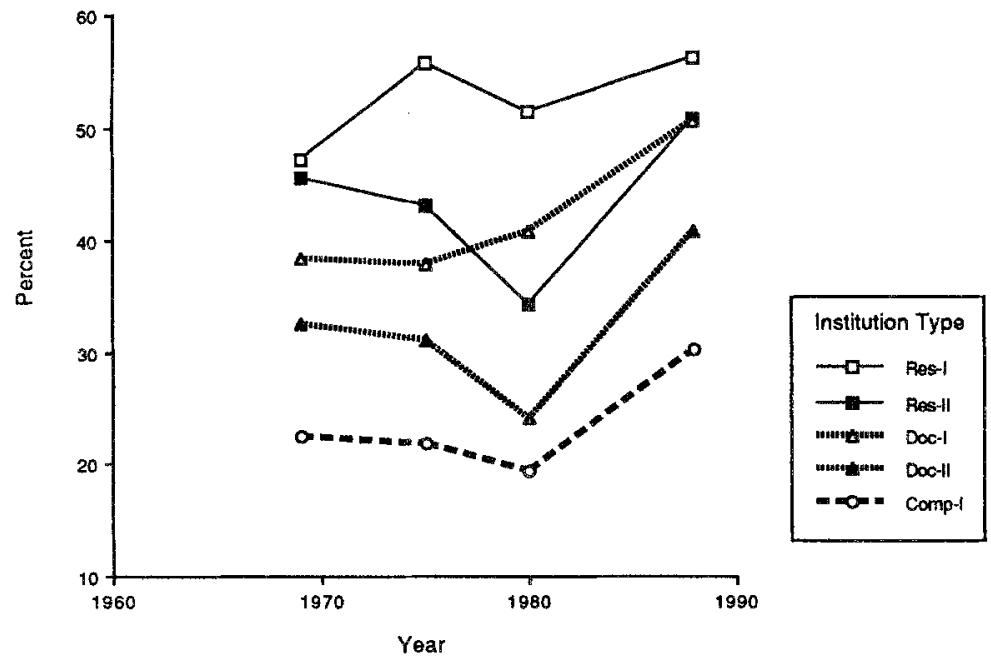

FIG. 7. Percent faculty with sponsored grants.

appear to be in a stronger competitive position with Res-II institutions when publication (PUB2YR and BKSALL) and grants (ALLGRT) output are aggregated (see Figure 9 and Table A9). After surpassing Res-II's in 1980, Doc-II's dropped slightly below the Res-II universities in 1988. Meanwhile, Res-I universities have retained their overall research output superiority since 1969. Scheffe tests showed significant differences between Res-I's and Res-II's in every year except 1969 (see Table 3).

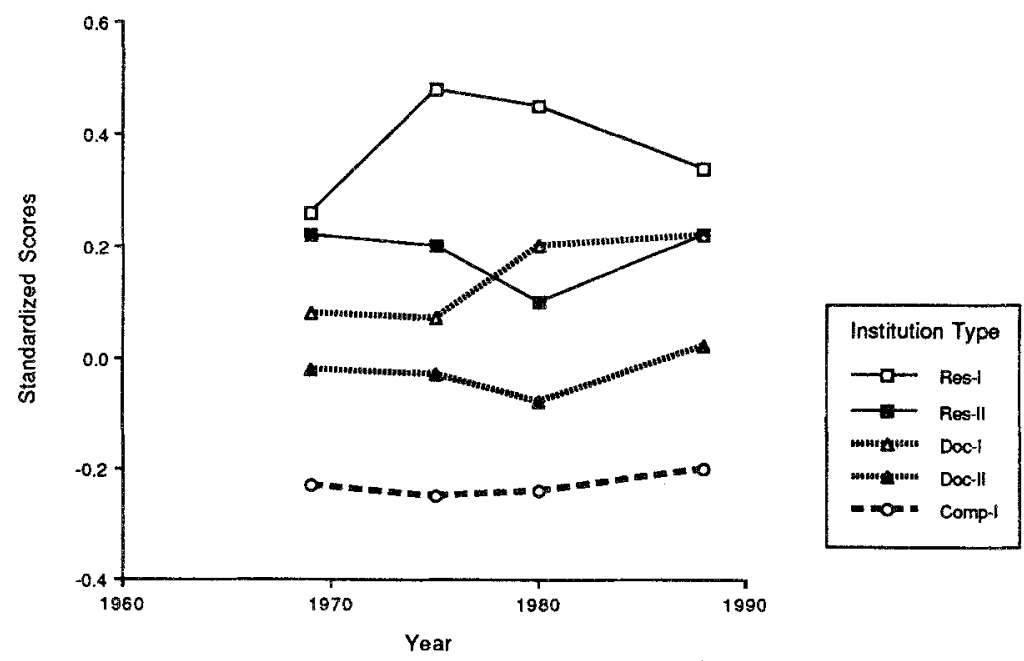

FIG. 8. Standardized sponsored grants (adjusted for differences by discipline). 


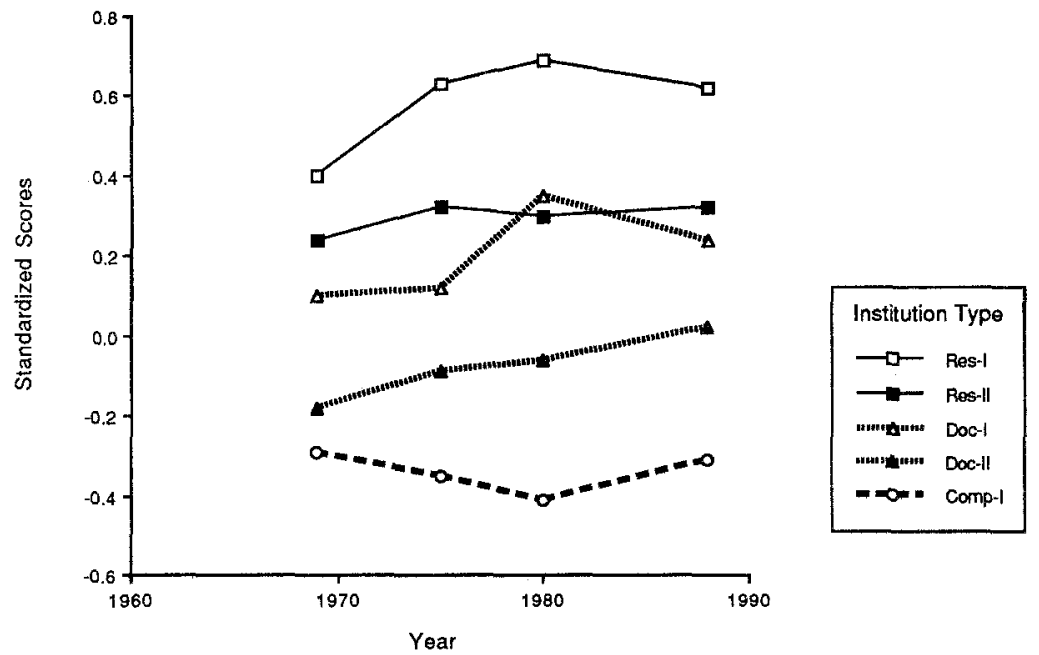

FIG. 9. Standardized publication and grant performance (adjusted for differences by discipline).

Overall research output has declined somewhat at Comp-I institutions, although there has been a slight upswing since 1980 (see Figure 9).

\section{DISCUSSION}

Over the past 20 years the emphasis on research has intensified at all five Carnegie types included in this study. This trend is reflected not only in their orientation toward research (more faculty holding Ph.D.'s and expressing a primary interest in research) but also in actual research output (grant and publication performance). For example, the mean number of lifetime books and publications in the past two years is up, while a greater percentage of faculty are receiving externally sponsored grant support.

While Res-I universities retain their dominant position in the hierarchy, other institutions, notably Res-II and Doc-I institutions, have enhanced their competitive position. The initial (1969) advantage of Res-I's has not accumulated. Perhaps the most interesting sign of competition arises from Doc-I institutions that are gaining on Res-II universities in competing for grants and in overall research performance-aggregate grants and publications.

At the same time, faculty at Comp-I institutions also have broadened their research emphasis. They produce more books and are obtaining more grants than in 1969. However, this growth in research output at Comp-l's has not matched that of other institutional types. In fact, Comp-I's have lost ground-in particular, with respect to Doc-II institutions.

Finally, the lack of any clear "winners" and "losers" of accumulated 
advantage may be due to constraints inherent in the study's unit of analysis that aggregates institutions by Carnegie type. The variation in publications within Carnegie type suggests that such aggregation may be too broad. In fact, it may be masking evidence of some institutions actually enjoying accumulative advantage. Therefore, to test institutional accumulative advantage, it may be more appropriate to track subgroups of institutions by other criteria such as publication output or levels of grant support. The similarity of publication output within departments suggests that departments, rather than institutions, may be a more conceptually sound method of analysis to assess the concept of accumulated advantage.

\section{NOTES}

1. Carnegie definitions vary somewhat over time (1973, 1976, 1987). Res-I's and Res-II's award at least 50 Ph.D.'s yearly. They are within the top 50 and 100 institutions, respectively, in receiving federal financial support. Doc-I's award a minimum of $40 \mathrm{Ph}$. D.'s and receive at least $\$ 3$ million in federal support, while Doc-II's award at least $20 \mathrm{Ph}$.D. 's yearly. Comp-I's enroll at least 2,000 students $(2,500$ in 1987) and offer the Masters as the highest degree.

2. The response rates of the 1969,1975 , and 1988 surveys were $60 \%, 52 \%$ and $50 \%$ respectively (see Table 1).

3. For each survey year, the number of faculty was estimated based on random samples dawn by Carnegie type, control, and department, yielding 80 separate cells (e.g., 1969, Res-I, public, biology). Furthermore, faculty estimates were compared with a similar sampling conducted by Bieber and Blackburn (1989) and were found to be alike.

4. Mean categorical publication values attenuate data for the highest-producing faculty (e.g., more than 10 publications). However, a comparison between recoded mean categorical values and the actual number of publications reported in 1988, the only survey with true interval publication data available, showed a high correlation (about .80 ) between the actual publications and recoded mean categorical values.

5. We also examined institutional and departmental support but these grants are excluded from our analysis.

6. Combining lifetime books and two-year publications may inadvertently result in some double counting. However, any such double counting of books published within the past two years is expected to be minimal.

7. All data in these national surveys are self-reported and hence are open to some measure of error. However, studies by Allison and Stewart (1974), Blackburn, Bobert, O'Connell, and Pellino (1980), and Clark and Centra (1982) checking vitae against self-reports of publications find faculty are generally fully honest in providing factual information about themselves.

8. Actually we know this is the case for psychologists and biologists and suspect it will turn out to be true for English faculty as well, the three disciplines used in the study.

9. ANOVA $F$-scores for all of the comparisons by Carnegie type reported in this paper are significant $(p<.001)$.

\section{REFERENCES}

Allison, P. D., and Stewart, J. A. (1974). Productivity differences among scientists: Evidence for accumulative advantage. American Sociological Review 39: 596-606. 
American Universities and Colleges (1968). Washington, DC: American Council on Education.

American Universities and Colleges (1983). Washington, DC: American Council on Education.

American Universities and Colleges (1987). Washington, DC: American Council on Education.

Bayer A. E. (1970). College and University Faculty: A Statistical Description (Vol. 5, No. 5). Washington, DC: American Council on Education.

Bayer, A. E., and Dutton, J. E. (1977, May-June). Career age and research-professional activities of academic scientists. Journal of Higher Education 48: 259-282.

Bieber, J., and Blackburn, R. T. (1989). Faculty research productivity 1972-1988: Development and application of constant units of measurement. Paper presented at the annual Association for the Study of Higher Education meeting. Atlanta, GA.

Biglan, A. (1973, June). The characteristics of subject matter in different academic areas. Journal of Applied Psychology 57(3): 195-203.

Blackburn, R. T., Behymer, C. E., and Hall, D. E. (1978). Correlates of faculty publications. Sociology Education 51: 132-141.

Blackburn, R. T., Bobert, A., O'Connell, C., and Pellino, G. R. (1980). Project for Faculty Development Program Evaluation. Ann Arbor: Center for the Study of Higher Education, University of Michigan.

Blackburn, R. T., and Lawrence, J. H. (1989). Faculty at Work: Final Report of the National Survey. Ann Arbor; National Center for Research to Improve Postsecondary Teaching and Learning.

Blackburn, R. T., Lawrence, J. H., Ross, S., Okoloko, V. P., Bieber, J., Meiland, R., and Street, Terry (1986). Faculty as a Key Resource. Ann Arbor: National Center for Research to Improve Postsecondary Teaching and Learning.

Bowen, H. R., and Schuster, J. H. (1986). American Professors: A National Resource Imperiled. New York: Oxford University Press.

Carnegie Commission on Higher Education (1973). A Classification of Institutions of Higher Education.

Carnegie Council on Policy Studies in Higher Education (1976). A Classification of Institutions of Higher Education, revised edition.

Carnegie Foundation for the Advancement of Teaching (1987). Carnegie foundation's classifications of more than 3,300 institutions of higher education. The Chronicle of Higher Education. 22-26, 28-30.

Clark, M. J., and Centra, J. A. (1982). Conditions Influencing the Career Accomplishments of Ph.D.s (ETS Research Report 82-18). Princeton: Educational Testing Service.

Cole, J. R., and Cole S. (1973). Social Stratification in Science. Chicago: University of Chicago Press.

Cole, S. S., Rubin, L., and Cole, J. R. (1978). Peer Review in the NSF: Phase I of a Study. Washington, DC: National Academy of Sciences.

Creswell, J. W. (1985). Faculty Research Performance (ASHE-ERIC Higher Education Report No. 4). Washington, DC: Association for the Study of Higher Education.

Drew, E. D., and Tronvig, J. A. (1988). Assessing the Quality of National Data About Academic Scientists. Claremont: The Claremont Graduate School, Claremont, CA.

Finkelstein, M. J. (1984). The American Academic Profession. Ohio: Ohio State University Press.

Graves, F. (1986, July/August). Hog heaven. Common Cause Magazine, pp. 17-23.

Higher Education Research Institute (1983). Technical Report to 1980 National Survey 
(exact title unknown). Los Angeles: Higher Education Research Institute, University of California, Los Angeles, CA.

Lazarsfeld, P. F., and Thielens, W., Jr. (1958). The Academic Mind: Social Scientists in a Time of Crisis. Glencoe, IL: Free Press.

Long, J. S. (December 1978). Productivity and academic position in the scientific career. American Sociological Review 43: 889-908.

Lotka, A. J. (1926). The frequency distribution of scientific productivity. Journal of the Washington Academy of Sciences 16(12): 317-323.

McCarthy, C. (1986, July 19). Pork with a Ph.D. The Washington Post.

Merton, R. K. (1968). The Matthew effect in science. Science 159: 56-63.

National Research Council (1987). Summary Report 1986: Doctorate Recipients from United States Universities. Washington, DC: National Academy Press.

National Science Foundation (1981). Science Indicators-1981. Washington, DC: National Science Board, National Science Foundation.

National Science Foundation (1987). Science and Engineering Indicators-1987. Washington, DC: National Science Board, National Science Foundation.

Price, D. (1963). Little Science, Big Science. New York: Columbia University Press.

Roizen, J., Fulton, O. and Trow, M. (1978). Technical Report: 1975 Carnegie Council National Surveys of Higher Education. Berkeley: Center for Studies in Higher Education, University of California.

Rose, R. M. (1986, October 8). Pork-barrel science vs. peer review. The Chronicle of Higher Education, p. 96.

Smith, B. L., and Karlesky, J. J. (1977). The State of Academic Science: Universities in the Nation's Research Effort. New York: Change Magazine Press.

Trow, M. A. (1975). Technical report on the 1969 Carnegie Commission survey of faculty and student opinion. Teachers and Students. Berkeley: The Carnegie Foundation for the Advancement of Teaching.

Wanner, R. A., Lewis, L. S., and Gregorio, D. I. (1981). Research productivity in academia: A comparative study of the sciences, social sciences, and humanities. Sociology of Science 54: 238-253.

Young, D. L., Blackburn, R. T., Conrad, C. F., and Cameron, K. S. (1989). Leadership, student effort, and department program quality: An exploration of quality across levels of analysis. Review of Higher Education 12(13): 265-278.

Zuckerman, H. (1977). Scientific Elite: Nobel Laureates in the United States. New York: Free Press.

Received January 24,1990 
TABLE A1. Percent of Faculty Holding PH.D.'s

\begin{tabular}{lcccc}
\hline & $\begin{array}{c}1969 \\
(N=3166)\end{array}$ & $\begin{array}{c}1975 \\
(N=3523) \\
\%\end{array}$ & $\begin{array}{c}1980 \\
(N=1493)\end{array}$ & $\begin{array}{c}1988 \\
(N=2383 \\
\%\end{array}$ \\
\hline Rarnegie Type & $\%$ & 95.6 & 96.0 & 97.9 \\
Res-II & 92.8 & 93.3 & 93.0 & 94.7 \\
Doc-I & 89.7 & 94.1 & 94.7 & 93.8 \\
Doc-II & 91.5 & 89.5 & 92.9 & 93.5 \\
Comp-I & 82.9 & 84.5 & 87.2 & 86.7 \\
Average & 72.9 & 89.2 & 91.0 & 90.8 \\
\hline
\end{tabular}

Note: Weighted data represent all faculty holding academic rank of assistant, associate, or full professor in eight departments (biology, chemistry, English, mathematics, political science, sociology, mathematics, and psychology).

TABLE A2. Percent of Faculty Primarily Interested in Research*

\begin{tabular}{lcccc}
\hline & $\begin{array}{c}1969 \\
(N=3166)\end{array}$ & $\begin{array}{c}1975 \\
(N=3523)\end{array}$ & $\begin{array}{c}1980 \\
(N=1493)\end{array}$ & $\begin{array}{c}1988 \\
(N=2383) \\
\%\end{array}$ \\
Carnegie Type & $\%$ & 66.8 & Data & 77.2 \\
\hline Res-I & 55.7 & 58.9 & not & 64.4 \\
Res-II & 52.1 & 55.1 & in & 50.9 \\
Doc-I & 43.7 & 41.9 & 1980 & 46.1 \\
Doc-II & 23.1 & 27.3 & survey & 25.1 \\
Comp-I & 20.7 & 42.9 & & 42.3 \\
Average & 36.3 & & & \\
\hline
\end{tabular}

* Faculty reported interests either "very heavily in research" or "in both (teaching and research) but leaning heavily toward research."

Note: Weighted data represent all faculty holding academic rank of assistant, associate, or full professor in eight departments (biology, chemistry, English, history, mathematics, political science, sociology, and psychology). 


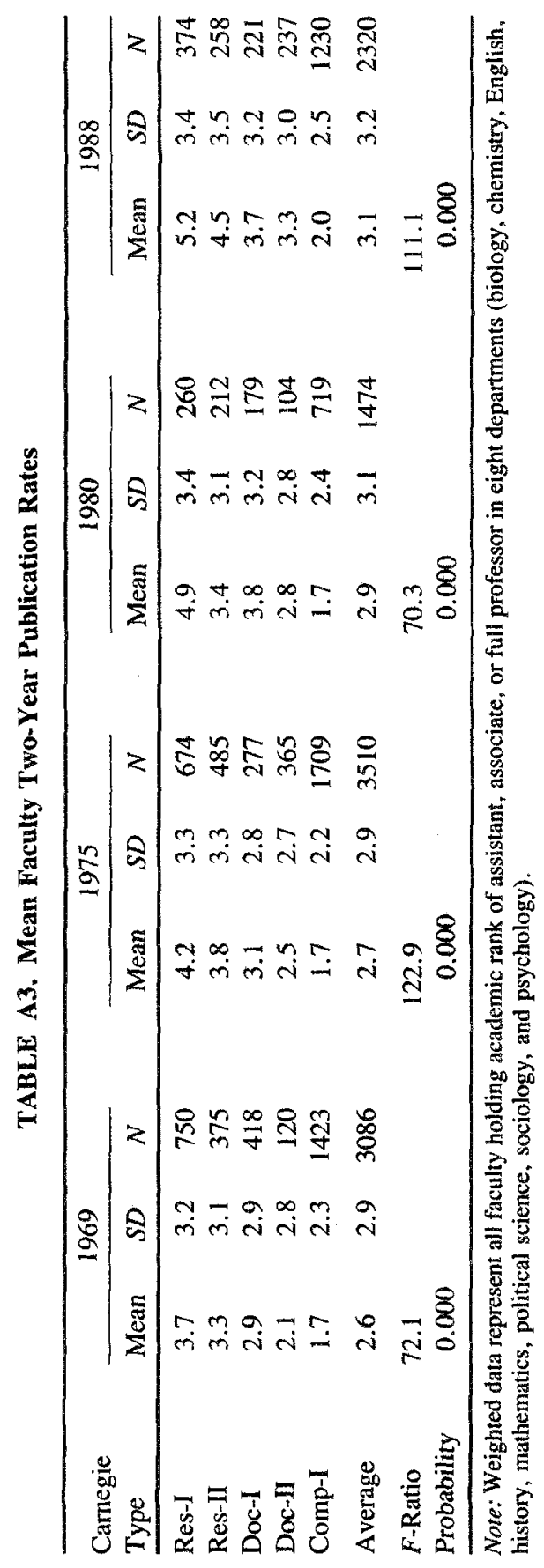




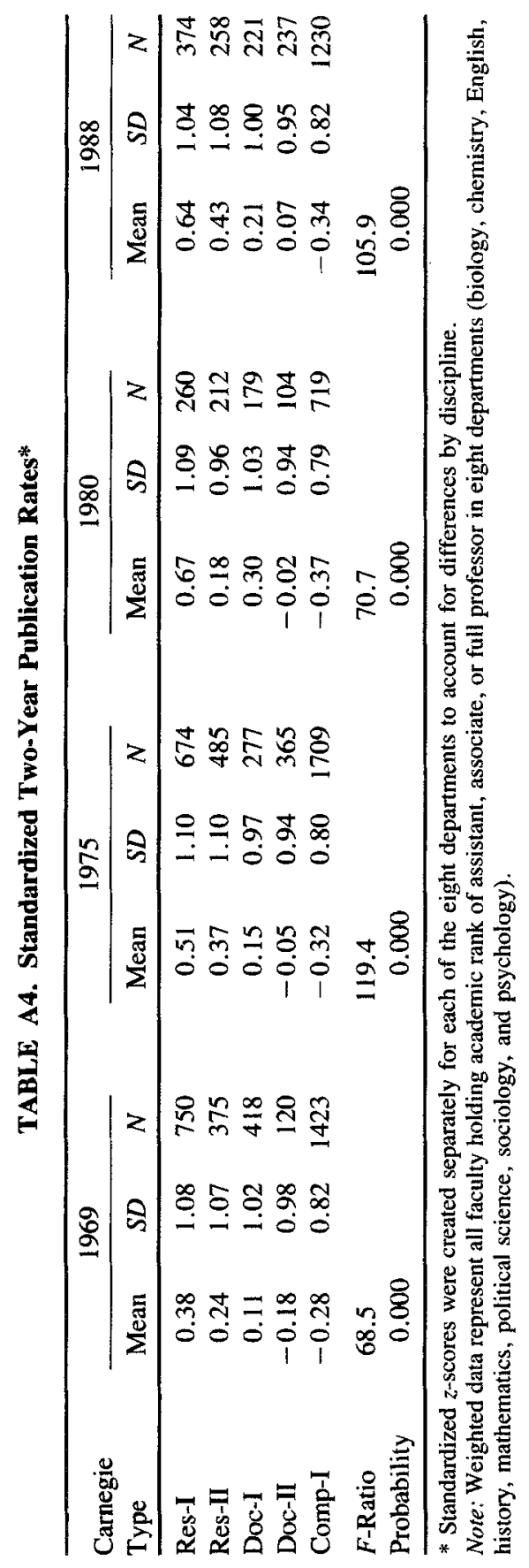




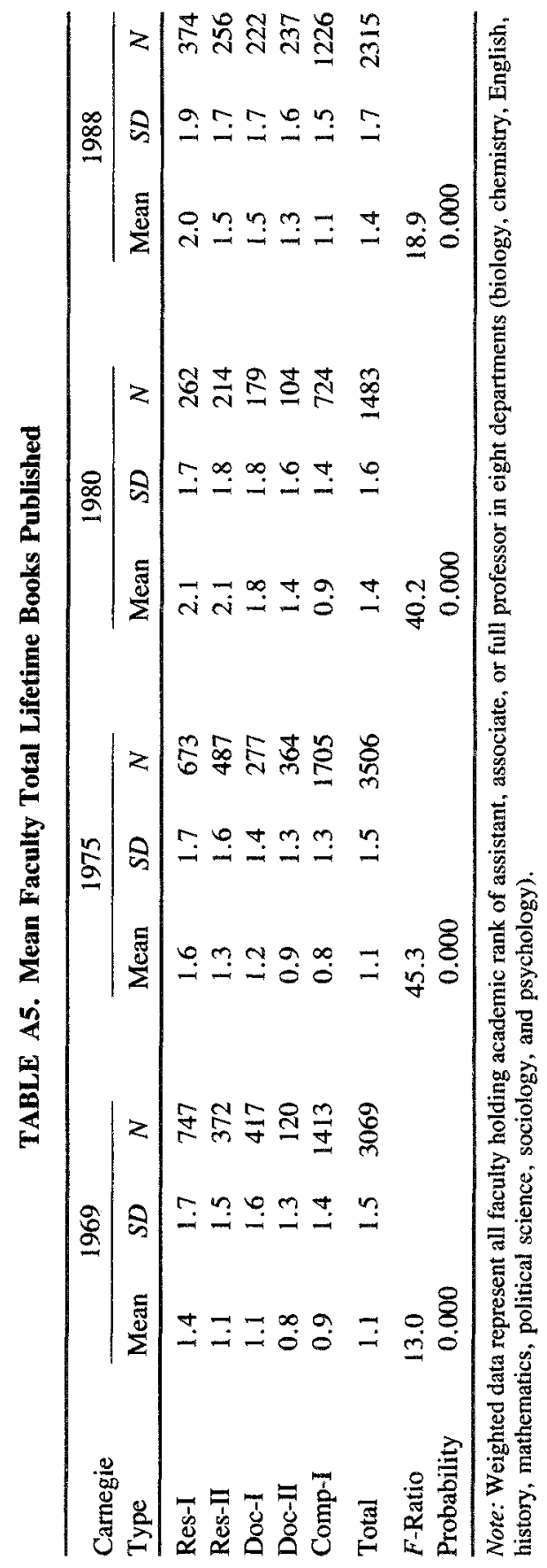




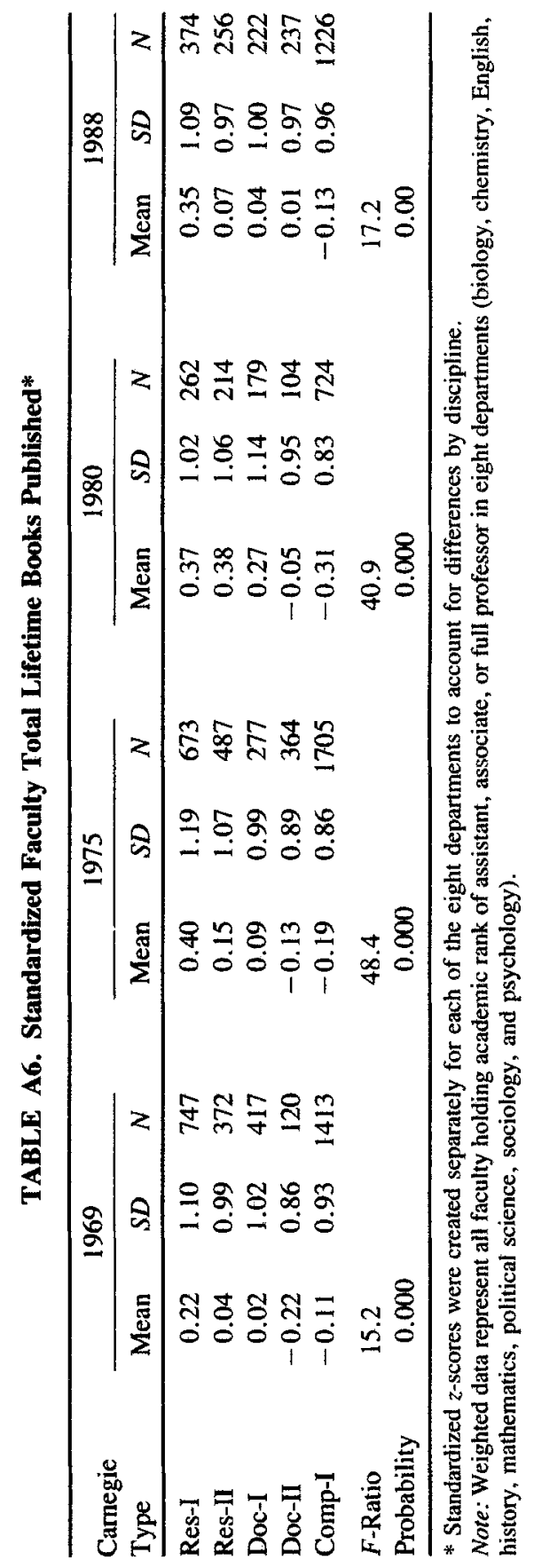


TABLE A7. Percent of Faculty Receiving Sponsored Grant Support

\begin{tabular}{|c|c|c|c|c|}
\hline Carnegie Type & $\begin{array}{c}1969 \\
(N=3166) \\
\%\end{array}$ & $\begin{array}{c}1975 \\
(N=3523) \\
\%\end{array}$ & $\begin{array}{c}1980 \\
(N=1493) \\
\%\end{array}$ & $\begin{array}{c}1988 \\
(N=2383) \\
\%\end{array}$ \\
\hline Res-I & 47.2 & 58.6 & 51.5 & 56.3 \\
\hline Res-II & 45.7 & 46.1 & 34.4 & 50.8 \\
\hline Doc-I & 38.4 & 40.3 & 40.9 & 50.7 \\
\hline Doc-II & 32.5 & 32.9 & 24.0 & 40.9 \\
\hline Comp-I & 22.4 & 23.3 & 19.3 & 30.3 \\
\hline Total & 34.0 & 35.7 & 30.1 & 40.0 \\
\hline
\end{tabular}

* Self-reported sources of external support include federal and state government, foundations, industry, and other sources received within the past year.

Note: Weighted data represent all faculty holding academic rank of assistant, associate, or full professor in eight departments (biology, chemistry, English, history, mathematics, political science, sociology, and psychology). 


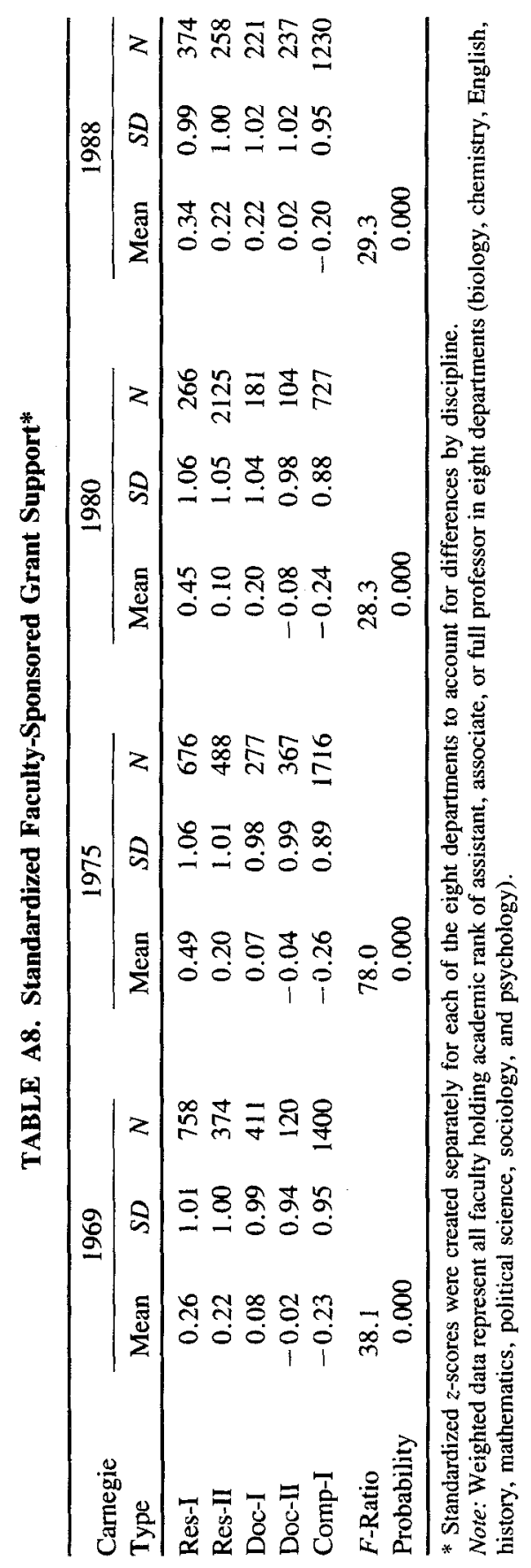




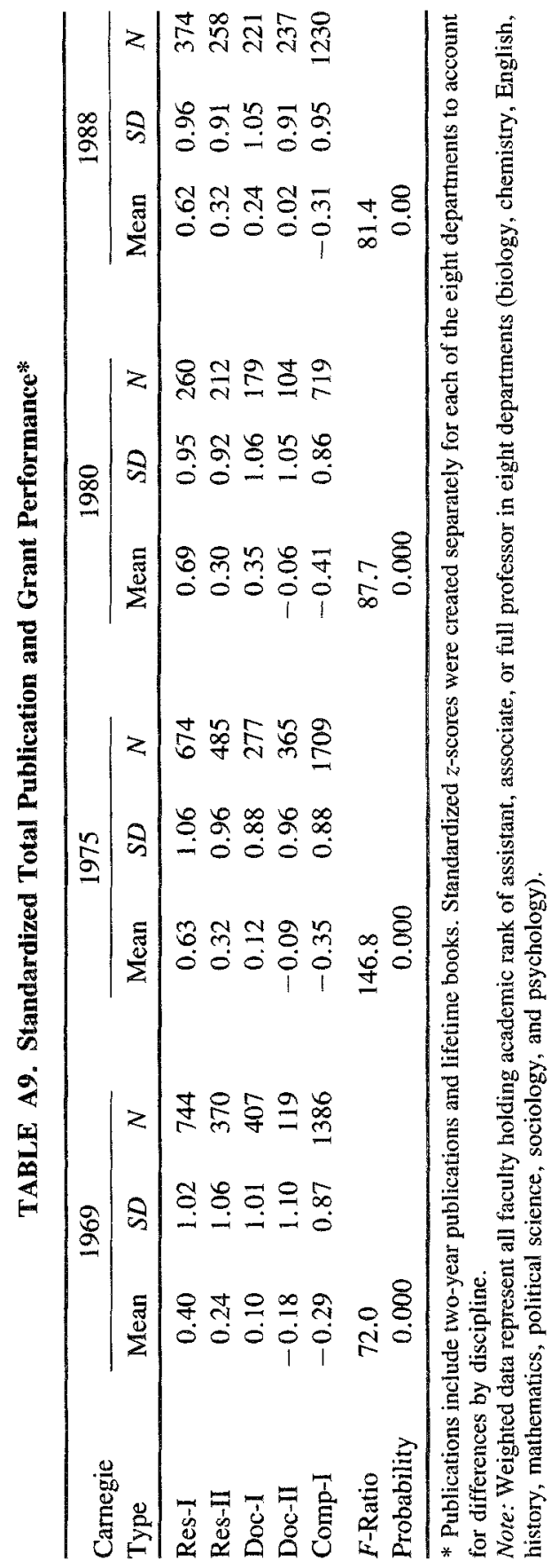

